\title{
Spinal Cord Hypothermia without Systemic Hypothermia
}

\author{
P.D. Purdy, R.L. Novakovic, B.P. Giles, S.L. Miller, and M.S. Riegel
}

\begin{abstract}
BACKGROUND AND PURPOSE: Hypothermia has been shown to be beneficial in the setting of acute SCl. However, widespread use has been hindered by the need for systemic hypothermia as the vehicle for achieving spinal cord hypothermia. This study demonstrates that localized spinal cord hypothermia can be achieved via a percutaneous approach while maintaining systemic normothermia.
\end{abstract}

MATERIALS AND METHODS: Five Yucatan swine underwent catheterization of the subarachnoid space and infusion of room temperature, chilled, and iced PL solutions into the cervical spinal canal, with drainage from the lumbar canal. Thermocouples were placed within the spinal cord and in the subarachnoid space and recorded during infusions and recovery from hypothermia.

RESULTS: Results demonstrated that hypothermia as low as $16.8^{\circ} \mathrm{C}$ is feasible in the spinal cord with retention of systemic normothermia, with strong $(r=0.95)$ correlation between the spinal cord temperature and the CSF temperature. Degrees of cooling varied with flow rates and with infusate temperature.

CONCLUSIONS: While the data are preliminary in a small group of animals, the ability to rapidly create a wide range of controlled spinal cord hypothermia while preserving normal body temperature warrants wider exploration. The study also indicates that further investigation of the hypothesis that CSF temperature monitoring may be an acceptable surrogate for direct spinal cord temperature monitoring should be pursued.

ABBREVIATIONS: $\mathrm{IB}=$ iced saline bath; $\mathrm{PIN}=$ percutaneous intraspinal navigation; $\mathrm{PL}=$ Plasma-Lyte $\mathrm{A} ; \mathrm{SCI}=$ spinal cord injury

S pinal cord cooling as a means of neuroprotection has been widely reported for many years. ${ }^{1-4}$ The most common setting has been traumatic and ischemic SCI. Some acknowledge the studies but question the finality of the proof. ${ }^{5}$ Furthermore, hypothermia is believed to be a protection against radiation injury. ${ }^{6}$ To date, the therapeutic implementation of hypothermia has required systemic hypothermia, owing to a lack of techniques for superselective cooling.

Purdy et $\mathrm{al}^{7}$ previously reported the technique of $\mathrm{PIN}^{8}$ in which the subarachnoid space is catheterized via lumbar puncture

Received February 14, 2012; accepted after revision April 2.

From the Departments of Radiology (P.D.P., R.L.N.), Neurological Surgery (P.D.P.), Neurology (R.L.N.), the Mobility Foundation Center (S.L.M.), and Animal Resources Center (M.S.R.), University of Texas Southwestern Medical Center, Dallas, Texas; and Department of Radiology (B.P.G.), Dallas Veterans Affairs Medical Center, Dallas, Texas:

This work was supported in part by the Mobility Foundation Center, University of Texas Southwestern Medical Center, Dallas, Texas.

Please address correspondence to Phillip D. Purdy, MD, Department of Radiology, UT Southwestern Medical Center, 5323 Harry Hines Blvd, Dallas, TX; e-mail: phillip.purdy@utsouthwestern.edu

--m Indicates open access to non-subscribers at www.ajnr.org

http://dx.doi.org/10.3174/ajnr.A3175 and navigated under fluoroscopic or endoscopic control. Implementation in a live swine model by using spinal endoscopy was recently reported. ${ }^{9}$ In this article, we report a novel technique for induction of localized spinal cord hypothermia using PIN via a cooled infusion of PL (Baxter Healthcare, Deerfield, Illinois) in the subarachnoid space in a live swine model.

\section{MATERIALS AND METHODS}

All procedures were performed in our animal angiography suite (Infinix CSI; Toshiba Medical Systems, Tokyo, Japan) by using a floor-mounted C-arm with a 9-inch image intensifier. Five female Yucatan swine, younger than 1 year of age, weighing $30-40 \mathrm{~kg}$ at the time of the experiment, underwent the following procedures.

A lumbar puncture was performed at the L2-3 or L3-4 interspace by using an angiographic micropuncture needle, and a micropuncture wire was advanced, over which the micropuncture catheter was introduced into the subarachnoid space. Leaving the micropuncture catheter in place (lumen size, 0.039 inch), we advanced a microcatheter (either Tracker 18, Boston Scientific, Natick, Massachusetts; or Prowler Plus, Cordis, Miami Lakes, Florida) coaxially via the micropuncture catheter under fluoro- 
scopic guidance. The catheter was placed so that the distal tip marker was at the C5-6 interspace level in the cervical spine. Subarachnoid placement was confirmed by injection of contrast material at that location and observation of myelographic images.

A second lumbar puncture was performed 1-2 interspaces inferior to the first by using a second micropuncture set. A standard J-wire was advanced cephalad in the subarachnoid space, and a $6 \mathrm{~F}$ angiographic sheath was placed in the subarachnoid space, with a standard catheter-exchange technique. Using the lumen of that sheath, we advanced a thermocouple microprobe (IT-23; Physitemp Instruments, Clifton, New Jersey), loaded into a microcatheter (Prowler Plus), to the C6-7 interspace by using PIN techniques. This apparatus was used to observe CSF temperatures.

A 5-inch spinal needle was preloaded with a second thermocouple microprobe so that the thermal element was at the level of the bevel of the spinal needle. Contrast was injected through the microcatheter placed during step 1. A myelogram was performed. Using myelographic guidance, we advanced an angiographic Seldinger needle from a lateral position toward the spinal canal at the C6-7 interspace level. Using the Seldinger needle as a guiding needle, we advanced the 21-gauge spinal needle coaxially and directed it into the spinal cord parenchyma (Fig $1 A,-B$ ). This apparatus was used to directly measure the temperature of the spinal cord. Measurements of both CSF and spinal cord temperatures were displayed on a multichannel temperature monitor (TH-8 Thermalert; Physitemp Instruments).

Following radiographic confirmation of placement of the above apparatus, PL was infused into the cervical subarachnoid space. These infusions used the microcatheter placed at C5-6 for introduction of fluid and used the open end of the $6 \mathrm{~F}$ sheath (2-mm lumen diameter) occupied by the temperature probe assembly (1-mm diameter) for withdrawal of fluid. Fluid was introduced by using a peristaltic pump (Masterflex, Model 77521-40; Cole Parmer Instruments, Vernon Hills, Illinois) and was withdrawn via gravity drainage by using the side port of the sheath. The following procedure was used in each animal:

1) Infusion for 30 minutes was conducted by using room temperature $\left(21^{\circ}-23^{\circ} \mathrm{C}\right) \mathrm{PL}$. Observations of core body temperature (rectal temperature probe), room temperature (wall thermometer), CSF temperature (subarachnoid probe), and spinal cord temperature (probe at C6-7) were recorded every 3 minutes during infusion.

2) Infusion was stopped for 15 minutes for thermal recovery, during which the above observations were continued every 3 minutes.

3) Infusion was repeated for 30 minutes, by using PL solution cooled in an on-site refrigerator (temperature, approximately $3^{\circ} \mathrm{C}$ ). Observations were continued every 3 minutes.
4) Infusion was stopped for 15 minutes, with continuation of observations per step 2 above.

5) Infusion was repeated for 30 minutes, by using the PL solution cooled in an ice chest (approximately $0^{\circ} \mathrm{C}$ ). An additional cooling intervention was added in the final infusion by inserting approximately $1 \mathrm{~m}$ of extension tubing between the pump and the infusion microcatheter and immersing that tubing in an IB. Observations were continued every 3 minutes. Additionally, experimentation with flow rates was conducted to observe the effects of variation of flow on observed temperatures. Specifically, in some animals, temperature observation in the IB infusion was continued until temperatures reached a lower plateau, at which time the flow rate was increased to observe further decrease in CSF and spinal cord temperature.

6) A final thermal recovery period was observed, with continuing observations every 3 minutes.

7) The animal was killed.

Temperatures were recorded as degrees Fahrenheit but converted to degrees Celsius for this study. Core body temperature was monitored throughout the procedure via a rectal probe. The entire procedure was conducted with the subject under general anesthesia administered by an on-site veterinarian. The study protocol was approved by the Institutional Animal Care and Use Committee.

\section{RESULTS}

Results are summarized in Table 1. The study was designed to prove the concept that intraspinal infusion can produce localized spinal cord cooling without systemic hypothermia and to define the degree of selective cooling possible. As such, a range of flow rates was used to achieve the maximum cooling. Simultaneous recordings of the lowest spinal cord temperature achieved at each flow rate and fluid temperature conditions are reported, as well as the flow rate at which these readings were obtained. All recorded room temperatures were between $21.7^{\circ}$ and $22.8^{\circ} \mathrm{C}$.

Table 2 shows the lowest achievable spinal cord temperature at each infusion temperature in each animal, with the corresponding core body temperature in each animal and the recovery time 
Table 1: Results from each animal with each infusion temperature ${ }^{\mathrm{a}}$

\begin{tabular}{ccccc}
\hline $\begin{array}{c}\text { Animal } \\
\text { No. }\end{array}$ & Temperature & $\begin{array}{c}\text { Low Cord } \\
\text { Temp }\end{array}$ & $\begin{array}{c}\text { CSF } \\
\text { Temp }\end{array}$ & $\begin{array}{c}\text { PL Flow } \\
\text { (mL/min) }\end{array}$ \\
\hline 1 & R & 31.9 & 30.2 & 2.0 \\
1 & I & 30.2 & 30.2 & 2.0 \\
1 & IB & 28.4 & 30.2 & 2.0 \\
2 & R & 29.1 & 30.8 & 6.4 \\
2 & I & 25.3 & 29.0 & 6.4 \\
2 & I & 21.1 & 25.4 & 8.0 \\
2 & IB & 22.2 & 26.7 & 6.4 \\
2 & IB & 16.8 & 22.6 & 8.0 \\
3 & R & 34.8 & 36.4 & 6.4 \\
3 & I & 32.8 & 34.7 & 6.4 \\
3 & IB & 28.1 & 30.8 & 6.4 \\
3 & IB & 22.6 & 28.1 & 11.0 \\
4 & R & 33.9 & 33.5 & 6.4 \\
4 & I & 31.9 & 32.8 & 6.4 \\
4 & IB & 28.7 & 29.9 & 6.4 \\
4 & IB & 18.8 & 21.0 & 16.6 \\
5 & R & 34.6 & 35.4 & 6.4 \\
5 & I & 34.7 & 35.7 & 6.4 \\
5 & IB & 31.6 & 34.6 & 6.4 \\
5 & IB & 21.8 & 26.7 & 17.6 \\
\hline
\end{tabular}

Note:-Temp indicates temperature; R, room temperature PL infusion; I, PL cooled in a refrigerator before infusion (temperature approximately $3^{\circ} \mathrm{C}$ ); IB, cooled PL passed through extension tubing coiled in an IB immediately prior to entering the microcatheter. This step was added to correct for any warming that occurred between the hanging bag and the microcatheter as the fluid passed via the pump.

a Temperatures reported are the lowest achieved spinal cord temperature, the recorded CSF temperature at the time that the lowest cord temperature was achieved, and the infusion flow rate at that same time. All temperatures are degrees Celsius. For animals in which different flow rates were attempted within a given infusion condition (R, I, or IB), low values for each flow rate within that infusion condition are reported.

Table 2: Demonstration of recovery times for each infusion temperature for the spinal cord temperature to rise to within $0.6^{\circ} \mathrm{C}\left(1^{\circ} \mathrm{F}\right)$ of the core body temperature, as measured by a rectal probe $^{a}$

\begin{tabular}{lcccc}
$\begin{array}{c}\text { Animal } \\
\text { No. }\end{array}$ & $\begin{array}{c}\text { Infusion } \\
\text { Temp }\end{array}$ & $\begin{array}{c}\text { Low Cord } \\
\text { Temp }\end{array}$ & $\begin{array}{c}\text { Body } \\
\text { Temp }\end{array}$ & $\begin{array}{c}\text { Recovery Time } \\
\text { (min) }\end{array}$ \\
\hline 1 & R & 31.9 & 34.3 & 9.0 \\
1 & I & 30.7 & 34.2 & 12.0 \\
1 & IB & 30.2 & 34.3 & 15.0 \\
2 & R & 29.1 & 35.5 & 9.0 \\
2 & I & 21.1 & 36.0 & 12.0 \\
2 & IB & 16.8 & 36.2 & 15.0 \\
3 & R & 34.8 & 38.0 & 6.0 \\
3 & I & 32.8 & 38.4 & 6.0 \\
3 & IB & 22.6 & 37.8 & 15.0 \\
4 & R & 33.9 & 37.4 & 3.0 \\
4 & I & 31.9 & 38.1 & 9.0 \\
4 & IB & 18.8 & 38.1 & 15.0 \\
5 & R & 34.6 & 36.8 & 3.0 \\
5 & I & 34.7 & 37.5 & 6.0 \\
5 & IB & 21.8 & 38.2 & 15.0 \\
\hline
\end{tabular}

Note:-Temp indicates temperature; R, room; I, PL cooled in a refrigerator before infusion (temperature approximately $3^{\circ} \mathrm{C}$ ); IB, cooled $\mathrm{PL}$ passed through extension tubing coiled in an IB immediately prior to entering the microcatheter. This step was added to correct for any warming that occurred between the hanging bag and the microcatheter as the fluid passed via the pump.

${ }^{a}$ Temperature measurements were obtained every 3 minutes during the observation period. Hence, recovery times are in 3-minute increments.

required for the spinal cord temperature to rise to within $0.6^{\circ} \mathrm{C}\left(1^{\circ} \mathrm{F}\right)$ of the core body temperature. A trend was seen for longer recovery times with greater temperature differences. Animal 1 developed a lower core temperature than subsequent animals, owing to our use of

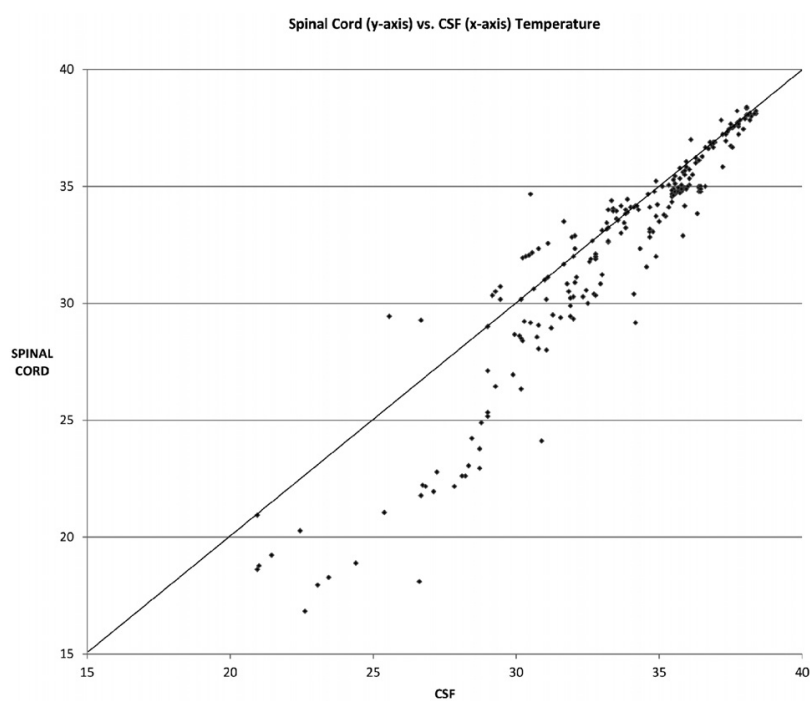

FIG 2. Scatterplot of spinal cord temperatures (y-axis) versus CSF temperatures ( $x$-axis) ( $n=255$ observations). Note the tendency at lower temperatures for CSF temperatures to be higher than spinal cord temperatures.

an external warming apparatus (Bair Hugger; Arizant Healthcare, Eden Prairie, Minnesota) in all subsequent animals.

To validate the use of CSF temperature as a surrogate marker of spinal cord temperature, we tested all temperature observations at all infusion temperatures and during recoveries for the correlation between CSF temperature and spinal cord temperature by using the Pearson correlation coefficient. This test returned a correlation of 0.95 between the CSF and spinal cord across all infusion and recovery conditions ( $n=255$ samples).

Due to the unreliability of a small subject cohort $(n=5)$, statistical analysis among different infusion temperatures (room temperature, cooled infusion, and IB) was not performed. However, the mean lowest spinal cord temperature achieved among the 5 animals by using room temperature infusion was $32.8^{\circ} \mathrm{C}$, whereas the mean lowest spinal cord temperature achieved in animals by using the IB was $21.7^{\circ} \mathrm{C}$ at each animal's respective highest flow rate. Multiple infusion flow rates within and between animals in this small series suggest improvement in cooling with higher flow rates, but detailed analysis exceeds the study design. However, these results suggest further variables for subsequent study.

Figure 2 shows results comparing CSF temperatures with spinal cord temperatures. While these temperatures were observed to be highly correlated ( $r=0.95$, Pearson correlation; $n=255$ observations), outlying values were observed, especially at lower spinal cord temperatures. As shown in the graph (Fig 2), at the spinal cord temperatures of $27^{\circ} \mathrm{C}$ or below, there were no instances of lower CSF readings than spinal cord readings.

\section{DISCUSSION}

Therapeutic hypothermia has been reported to be beneficial or potentially beneficial in many settings, including acute traumatic SCI and spinal cord ischemia either from trauma or during aortic surgery. ${ }^{10}$ Dietrich et $\mathrm{al}^{11}$ recently reviewed hypothermia as a protective strategy, noting the demonstrated advantages of hypothermia while pointing out the complexities imposed by 
management or avoidance of complications of systemic hypothermia.

Means of application of hypothermia in humans has varied from systemic hypothermia to localized cooling of a surgically exposed, injured spinal cord. ${ }^{2,12}$ Theoretic works have advocated placement of a cooling pad against the skin along the spine to achieve cooling. ${ }^{13} \mathrm{Ha}$ and $\mathrm{Kim}^{14}$ also described placement of an epidural cooling infusion as a means of achieving moderate $\left(30^{\circ} \mathrm{C}\right)$ cooling in rats. Using a weight-drop model for injury, they demonstrated decreased apoptosis and improved functional outcomes when hypothermia was applied. Baird et $\mathrm{al}^{6}$ studied hypothermia in hibernating ground squirrels and demonstrated protective effects against radiation injury.

An alternative for achieving spinal cord hypothermia without systemic hypothermia is epidural cooling, either by infusion or by use of a cooling apparatus that does not infuse fluids. This has been most prominent in studies of spinal cord cooling to prevent injury during aortic cross-clamping. Casas et $\mathrm{al}^{15}$ used cold saline infusion to achieve epidural temperatures in rats as low as $24^{\circ} \mathrm{C}$ but did not measure subarachnoid or spinal cord temperatures.

In a group of studies using a closed hypothermic system in pigs, Mori et al ${ }^{16}$ used a closed-loop catheter system to circulate iced saline in the epidural space to achieve subarachnoid cooling as low as $27.9^{\circ} \mathrm{C}$. Yoshitake et $\mathrm{al},{ }^{17}$ from the same institution as Mori et al, repeated a trial with that system in pigs to circulate hypothermic saline at $4^{\circ} \mathrm{C}$, achieving subarachnoid temperatures as low as $20.8^{\circ} \mathrm{C}$ at L4, though both groups performed a partial laminectomy and ligamentum flavum removal to allow entry of their catheter system. In another study from that group, Ishikawa et $\mathrm{al}^{18}$ showed decreased reactive hyperperfusion following aortic unclamping and postulated induction of nitric oxide synthase as a protective mechanism.

Tabayashi et al ${ }^{19}$ studied canines by using a chilled saline epidural perfusion $\left(10.5^{\circ} \mathrm{C}\right)$. In preliminary studies, they achieved spinal cord temperatures between $26^{\circ}$ and $31^{\circ} \mathrm{C}$ when the systemic temperature was $31.6^{\circ}-33.5^{\circ} \mathrm{C}$. In their subsequent experimental group studied by using that paradigm, they observed a neuroprotective effect of perfusion. In rabbits, Martelli et $\mathrm{al}^{20}$ used cooled saline infusions at different temperatures, as low as $17^{\circ} \mathrm{C}$. In this study, iced saline was infused at rates of $5 \mathrm{~mL} / \mathrm{min}$. Fluid was vented inferiorly via drainage from the laminectomy site. These authors placed 2 temperature probes in the spinal cord of each animal and observed temperatures as low as $9.2^{\circ} \mathrm{C}$. One animal in the study died of elevated intracranial pressure, attributed by the authors to inadequate opening of the epidural space to permit venting of the fluid. Animals weighed from 2.8 to $3.3 \mathrm{~kg}$. Protective effects of hypothermia were shown in this study as well.

In humans, Cambria et $\mathrm{al}^{21}$ reported 170 patients undergoing aortic aneurysm surgery in whom epidural iced saline infusion produced subarachnoid cooling to a mean temperature of $26.4^{\circ} \mathrm{C}$ (range, $21.1^{\circ}-37.4^{\circ} \mathrm{C}$ ). They showed improved neurologic results (SCI rate of $7 \%$ versus a predicted incidence of $18.5 \%$ ). They also showed a rise in CSF pressure from $13.3 \mathrm{~mm} \mathrm{Hg}$ baseline mean to $35.1 \mathrm{~mm} \mathrm{Hg}$ during cross-clamp.

The authors of this study realize that profound hypothermia as a means of treatment is controversial. They also believe the above data support the anticipated benefit. The more advanced experience involves modest hypothermia. Levi et $\mathrm{al}^{22}$ reported clinical experience with modest systemic hypothermia $\left(33^{\circ} \mathrm{C}\right)$ in 14 pa- tients treated for an average of 93.6 hours. Time to achieve cooling averaged 2.72 hours. More profound hypothermia was not tested. While our approach is significantly more robust in terms of rapidity and depth of cooling, we recognize inherent risks with direct instrumentation and infusion of the spinal canal. The current "proof of concept" study requires much further technical experimentation, development of less invasive means to monitor temperatures, and greater investigation of protocols of infusion. However, the demonstration of rapid, profound cooling without systemic hypothermia warrants exploration.

In the current study, hypothermia ranging from mild to deep in the CSF and spinal cord was demonstrated by using a hypothermic subarachnoid circulation system in which a commercially available infusate (PL) was cooled and infused into the cervical spinal canal and removed from the lumbar subarachnoid space in a large-animal model (swine). The potential to use thermal monitoring of CSF temperature as a surrogate for spinal cord temperature is suggested by the strong correlation between temperatures at these sites and by substantive agreement between these at many temperatures. The differences between CSF and spinal cord temperatures at lower readings may simply be a function of cephalocaudal gradation during infusion, but other factors cannot be excluded and further investigation is indicated. However, the potential to achieve spinal cord hypothermia without induction of systemic hypothermia is clear. Infusion catheters with multiple side holes may enable greater homogeneity of thermal impact over a greater length of the spinal canal.

Other clarifications are needed. While changes in rates of infusion appear to affect degrees of cooling, more data are required. We do not know the degree of gradation in temperature in locations increasingly remote from the site of infusion. Because the fluid withdrawal site was caudal to the infusion site in this study, we assumed that the primary cooling was achieved caudal to the tip of the infusion catheter. However, as spinal cord temperature readings descended into the mid-20s, we noted that the animals' spontaneous respirations decreased and they tended to require mechanical ventilation at those levels and below. We hypothesize that there may be some degree of ascending cooling, but this was not tested in this study.

While the benefit of subarachnoid-versus-epidural infusion remains to be shown, the authors do not believe that the approaches allow only 1 solution. In aortic cross-clamping, epidural infusion is supported by both animal and human experience, and subarachnoid infusion is untested, to our knowledge. However, in epidural pathologies (trauma, tumors), epidural infusion would be expected to be less applicable and subarachnoid infusion may prove advantageous. Additionally, with further technical development, the option for pharmacologic solutions combined with hypothermia may arise with the subarachnoid technique.

Because we were placing a needle in the spinal cord to monitor spinal cord cooling, this was designed as a nonsurvival study. Hence, clinical effects of hypothermia were not tested here, and recovery times at varying degrees of hypothermia were not the subject of this study. In addition, it would be desirable to know the effects on subarachnoid pressures of infusions at different rates. Interpretation of pressure effects would be complicated by success or failure at matching withdrawal rates to infusion rates (ie, tech- 
nical difficulties versus biologic effects of the infusion). More extensive investigation is warranted, in addition to improving iterations of the infusion system. Simultaneously, the potential to achieve therapeutic degrees of hypothermia without the difficulties imposed by systemic hypothermia compels pursuit of this technique.

The discrepancy between spinal cord and CSF temperatures at the lower observed values warrants investigation. Possible explanations include lamination of flow of the cold infusate that was undetected by the temperature probe or placement of the temperature probe caudal to the spinal cord probe, with cephalocaudal warming as the infusate descended in the spinal canal. In 2 animals in our study (animals 2 and 3), the CSF temperature probe was observed to withdraw to a more caudal location (2- to $4-\mathrm{cm}$ withdrawal) during manipulations in the study, but the higher CSF-versus-spinal cord temperature observation was not limited to those animals.

Our decision to use PL as the infusate for this study was prompted by availability in our lab, the relatively isosmolar and $\mathrm{pH}$-balanced nature of the fluid, and the nonsurvival nature of the study. However, subsequent review demonstrated that lactated Ringer's solution is a more widely used compound and has been reported in neurosurgery procedures in both animals and humans, ${ }^{23-26}$ primarily as an irrigant during endoscopic procedures. Salvador et $\mathrm{al}^{27}$ evaluated normal saline as an irrigant and found significant disruptions of CSF chemistry. We plan to use lactated Ringer's in future studies.

\section{CONCLUSIONS}

With PIN, it is feasible to induce significant spinal cord hypothermia without coincident induction of systemic hypothermia. While this work demonstrates the concept, infusion paradigms and improved means of monitoring temperatures remote from the thermocouples used in this study must be developed. In addition, more noninvasive means of monitoring are desirable. Clinical efficacy remains to be determined, but this promising initial work warrants further investigation.

Disclosures: Phillip Purdy_OTHER RELATIONSHIPS: Through my institution, I am an inventor on patents that relate to the technology relevant to this submission. However, there was no financial support related to these patents. Roberta NovakovicUNRELATED: Travel/Accommodations/Meeting Expenses Unrelated to Activities Listed: ev3, New Era International Multidisciplinary Sharing, Comments: Pipeline training course in Florida. Hotel cost reimbursement (travel). Platform presentation, hotel, and travel arranged by New Era International Multidisciplinary Sharing at the 2011 meeting in Zhengzhou, China.

\section{REFERENCES}

1. Fu ES, Tummala RP. Neuroprotection in brain and spinal cord trauma. Curr Opin Anaesthesiol 2005;18:181-87

2. Hansebout RR, Tanner JA, Romero-Sierra C. Current status of spinal cord cooling in the treatment of acute spinal cord injury. Spine (Phila Pa 1976) 1984;9:508-11

3. Inamasu J, Ichikizaki K. Mild hypothermia in neurologic emergency: an update. Ann Emerg Med 2002;40:220-30

4. Kuffler DP. Combinatorial techniques for enhancing neuroprotection: hypothermia and alkalinization. Ann N Y Acad Sci 2010;1199:164-74

5. Kwon BK, Mann C, Sohn HM, et al, and the NASS Section on Biologics. Hypothermia for spinal cord injury. Spine $J$ 2008;8:859-74
6. Baird BJ, Dickey JS, Nakamura AJ, et al. Hypothermia postpones DNA damage repair in irradiated cells and protects against cell killing. Mutat Res 2011;711:142-49

7. Purdy PD, Replogle RE, Pride GL Jr, et al. Percutaneous intraspinal navigation (PIN): feasibility study of a new and minimally invasive approach to the spinal cord and brain in cadavers. AJNR Am J Neuroradiol 2003;24:361-65

8. Fujimoto T, Giles BP, Replogle RE, et al. Visualization of sacral nerve roots via percutaneous intraspinal navigation (PIN). AJNR Am J Neuroradiol 2005;26:2420-24

9. Purdy P, Welch B, Novakovic R, et al. A live swine model for development of techniques using percutaneous intraspinal navigation. In: Proceedings of the XIX Symposium Neuroradiologicum, Bologna, Italy. October 4-9, 2010

10. Dietrich WD III. Therapeutic hypothermia for spinal cord injury. Crit Care Med 2009;37(suppl.):S238-42

11. Dietrich WD, Levi AD, Wang M, et al. Hypothermic treatment for acute spinal cord injury. Neurotherapeutics 2011;8:229-39

12. Albin MS, White RJ, Yashon D, et al. Effects of localized cooling on spinal cord trauma. J Trauma 1969;9:1000-08

13. Smith KD, Zhu L. Theoretical evaluation of a simple cooling pad for inducing hypothermia in the spinal cord following traumatic injury. Med Biol Eng Comput 2010;48:167-75

14. Ha KY, Kim YH. Neuroprotective effect of moderate epidural hypothermia after spinal cord injury in rats. Spine (Phila $\mathrm{Pa} 1976$ ) 2008;33:2059-65

15. Casas CE, Herrera LP, Prusmack C, et al. Effects of epidural hypothermic saline infusion on locomotor outcome and tissue preservation after moderate thoracic spinal cord contusion in rats. J Neurosurg Spine 2005;2:308-18

16. Mori A, Ueda T, Hachiya T, et al. An epidural cooling catheter protects the spinal cord against ischemic injury in pigs. Ann Thorac Surg 2005;80:1829-34

17. Yoshitake A, Mori A, Shimizu H, et al. Use of an epidural cooling catheter with a closed countercurrent lumen to protect against ischemic spinal cord injury in pigs. J Thorac Cardiovasc Surg 2007;134:1220-26

18. Ishikawa A, Mori A, Kabei N, et al. Epidural cooling minimizes spinal cord injury after aortic cross-clamping through induction of nitric oxide synthase. Anesthesiology 2009;111:818-25

19. Tabayashi K, Niibori K, Konno H, et al. Protection from postischemic spinal cord injury by perfusion cooling of the epidural space. Ann Thorac Surg 1993;56:494-98

20. Martelli E, Cho JS, Mozes G, et al. Epidural cooling for the prevention of ischemic injury to the spinal cord during aortic occlusion in a rabbit model: determination of the optimal temperature. J Vasc Surg 2002;35:547-53

21. Cambria RP, Davison JK, Carter C, et al. Epidural cooling for spinal cord protection during thoracoabdominal aneurysm repair: a fiveyear experience. J Vasc Surg 2000;31:1093-102

22. Levi AD, Green BA, Wang MY, et al. Clinical application of modest hypothermia after spinal cord injury. J Neurotrauma 2009;26: 407-15

23. Aken JV, Struys M, Verplancke T, et al. Cardiovascular changes during endoscopic third ventriculostomy. Minim Invas Neurosurg 2003;46:198-201

24. Derbent A, Ersahin Y, Yurtseven T, et al. Hemodynamic and electrolyte changes in patients undergoing neuroendoscopic procedures. Childs Nerv Syst 2006;22:253-57

25. Fabregas N, Craen RA. Anaesthesia for endoscopic neurosurgical procedures. Curr Opin Anaesthesiol 2010;23:568-75

26. Klopp LS, Ridgway M. Use of an endoscope in minimally invasive lesion biopsy and removal within the skull and cranial vault in 2 dogs and 1 cat. J Am Vet Med Assoc 2009;234:1573-77

27. Salvador L, Valero R, Carrero E, et al. Cerebrospinal fluid composition modifications after neuroendoscopic procedures. Minim Invas Neurosurg 2007;50:51-55 